1 Detecting a moorland wildfire scar in the Peak District, UK, using 2 Synthetic Aperture Radar (SAR) from ERS-2 and Envisat ASAR

7 Gail Millin-Chalabi, MG.57 Devonshire House, Oxford Road, University of

8 Manchester, M13 9QH, Gail.Millin-Chalabi@ manchester.ac.uk

9 Keywords: Fire scars, SAR, Multitemporal, Precipitation, Moorlands, Bleaklow

*Corresponding author. Email: Gail.Millin-Chalabi@manchester.ac.uk 


\title{
Detecting a moorland wildfire scar in the Peak District, UK, using Synthetic Aperture Radar (SAR) from ERS-2 and Envisat ASAR
}

\author{
GAIL MILLIN-CHALABI ${ }^{*} \dagger+$ JULIA MCMORROW $\ddagger$ and CLIVE AGNEW $\ddagger$ \\ $\dagger$ Mimas, University of Manchester, Oxford Road, Manchester M13 9QH, UK \\ \$ School of Environment and Development, University of Manchester, PO Box 88, \\ Manchester M60 1QD, UK
}

\begin{abstract}
Wildfires occur annually in UK moorland environments, especially in drought years. They can be severely damaging to the ecosystem when they burn deep into the peat, killing ground-nesting birds and releasing $\mathrm{CO}_{2}$ into the atmosphere. Synthetic Aperture Radar (SAR) was evaluated for detecting the 18 April 2003 Bleaklow wildfire scar $\left(7.4 \mathrm{~km}^{2}\right)$. SAR's ability to penetrate cloud is advantageous in this inherently overcast area. SAR can provide fire scar boundary information which is otherwise labour intensive to collect in the field using a Global Positioning System (GPS). This paper evaluates the potential of SAR intensity and InSAR coherence to detect a large peat moorland wildfire scar in the Peak District of northern England. A time-series of pre-fire and post-fire ERS-2 and ASAR Single Look Complex (SLC) data were pre-processed using SARScape 4.2 to produce georeferenced greyscale images. SAR intensity and InSAR coherence values were analysed against CORINE land cover classes and precipitation data. SAR intensity detected burnt peat well after a precipitation event and for previous fire events within the CORINE peat bog class. For 18 April 2003 fire event intensity increased to $0.84 \mathrm{~dB}$ post-fire inside the fire scar for the peat bog class. InSAR coherence peaked post-fire for moors and heathland and natural grassland classes inside the fire scar, but peat bog exposed from previous fires was less responsive. Overall, SAR was found to be effective for detecting the Bleaklow moorland wildfire scar and monitoring wildfire scar persistence in a degraded peat landscape up to 71 days later. Heavy precipitation amplified the SAR fire scar signal, with precipitation after wildfires being typical in UK moorlands. Further work is required to disentangle the effects of fire size; topography and less generalised land cover classes on SAR intensity and InSAR coherence for detecting fire scars in degraded peat moorlands.
\end{abstract}

\section{Introduction}

UK moorland wildfires need to be monitored as they can burn deep into the peat releasing $\mathrm{CO}_{2}$ into the atmosphere, contributing to greenhouse gas emissions, and hence global warming. In addition the UK Climate Impacts Programme (UKCIP) suggest a 1$5^{\circ} \mathrm{C}$ increase in average summer temperatures, increasing the probability of wildfire frequency (McEvoy et al. 2006). Wildfires result in fire scars producing areas of exposed peat which release Dissolved Organic Carbon (DOC) into nearby streams, causing discolouration to drinking water supply and requiring costly restoration (Worrall and Evans 2009). It is important to detect wildfire scars in moorland habitats to understand their size, distribution and persistence in the landscape because this information can help inform moorland restoration projects and ecosystem changes (Anderson et al. 2009).

Remotely sensed data may offer an alternative and more cost effective approach to map and monitor moorland wildfire scars at the landscape scale, potentially providing consistent information on fire size, persistence of wildfire scars, and variation in burn severity within them. However, in UK moorlands optical remote sensing is limited by

*Corresponding author. Email: Gail.Millin-Chalabi@manchester.ac.uk 
frequent cloud cover (Armitage et al. 2007, Legg 1991). Thermal hotspot detection using MODIS (250m resolution) can miss these fires; for instance, the $0.8 \mathrm{~km}^{2}$ Wainstalls fire in West Yorkshire 30 May 2011, as shown by analysis of hotspot data from the European Forest Fire Information System (EFFIS 2011).

The use of SAR for wildfire scar detection in a UK moorland environment has not yet been fully explored and provides a unique line of enquiry. The benefits of SAR data are that as an active system it can penetrate cloud and images can be acquired both day and night, improving temporal resolution (Rykhus and Zhong 2011). SAR has previously been used effectively for fire scar detection in boreal (Bourgeau-Chavez et al. 2002, 2007), savannah (Menges et al. 2004), Mediterranean (Gimeno et al. 2004) and tropical (Huang and Siegert 2004) environments however not in a UK moorland environment.

The Peak District National Park (PDNP) is one of the few moorland areas in the UK where wildfire scar perimeters are systematically mapped using a Global Positioning System (GPS); perimeters have been recorded by rangers since 2003. Point data of the approximate centre of the fire ground has also been collected by rangers since 1976 (CCVE 2005). The PDNP is therefore a good case study, providing essential ground truth data on fire perimeter and fire history. In other moorland landscapes, spatially-robust data on wildfire scars is lacking due to the operational difficulties of getting to locations and the lack of labour to map the wildfire scars in the field. The aim of this paper is to explore whether C-band SAR data can be used to detect a significant wildfire scar in a UK degraded moorland landscape. It uses the case study of the 18 April 2003 fire, which burnt deep into the peat on the Bleaklow plateau in the PDNP. The fire scar was GPS-mapped by the PDNP rangers as $7.4 \mathrm{~km}^{2}$ in area with a $28 \mathrm{~km}$ perimeter (figure 1). The objectives of the paper are:

(i) To assess the temporal detectability of the Bleaklow 2003 wildfire scar using the SAR parameters of intensity and InSAR coherence for a time series of greyscale georeferenced ERS-2 and ASAR images;

(ii) To identify compare and contrast spatial patterns in SAR intensity and InSAR coherence signals inside and outside the fire scar.

(iii) To relate SAR spatial and temporal patterns to CORINE land cover classes and precipitation.

\section{Methodology}

\subsection{Study area}

The PDNP is one of the most degraded moorland landscapes in the UK (McEvoy et al. 2006) and hence it is vulnerable to the effects of climate change as modelled by the UK Climate Impacts Programme (UKCIP) (McMorrow et al. 2009). Bleaklow is part of the Dark Peak situated between the conurbations of Manchester to the west and Sheffield to the east. It is classed as an upland moorland environment with significant peat bog coverage and only small areas of coniferous forest to the south and north-west of the $71.93 \mathrm{~km}^{2}$ study site (figure 1). The habitat therefore differs significantly for fire scar detection using SAR from the boreal forested areas in Alaska, Canada and Russia studied by Bourgeau-Chavez et al. (1997, 2002, 2007) and Kasischke et al. (2007). The Bleaklow plateau is of high scientific importance which is reflected in its multiple statutory designations to protect habitat and wildlife; for example the vegetation of mosses (Sphagnum spp.), heather (Calluna vulgaris) and cotton-grass (Eriophorum spp.) and upland birdlife such as the Golden Plover (Pluvialis apricaria) and Dunlin (Calidris alpine). Sphagnum spp. is essential for carbon sequestration with the 
underlying peat being a major carbon store and supporting ecosystem services, which wildfires can destroy (Evans and Lindsay 2010).

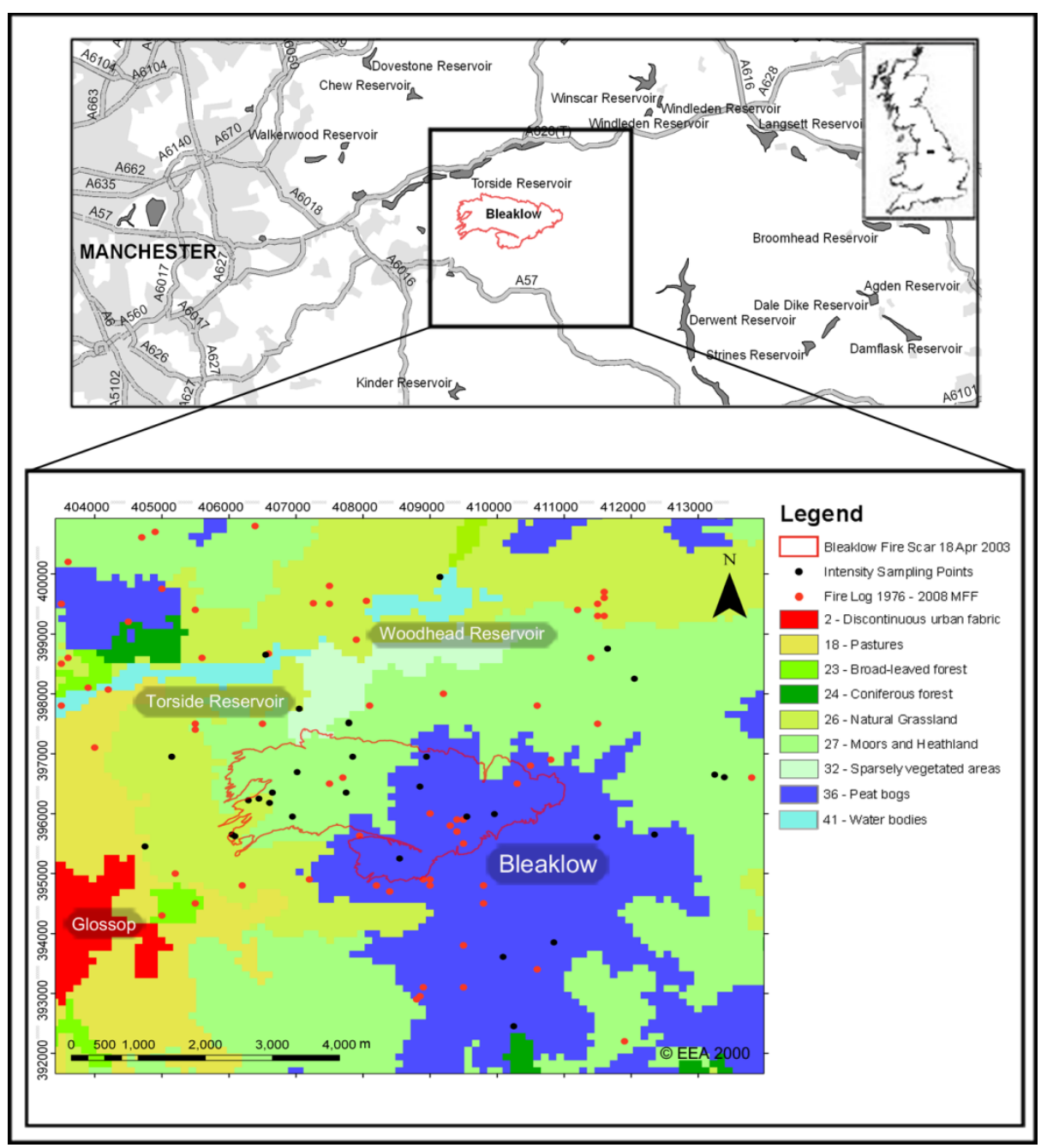

Figure 1. CORINE land cover data for Bleaklow, Peak District National Park, northwest England, and showing: GPS outline of the 18 April 2003 fire scar in red; fire log point data 1976 to 2008 courtesy of Moors for the Future (MFF) as red dots; and intensity/coherence sampling points as black dots.

\subsection{SAR data selection}

A time series of ERS-2 and Advanced Synthetic Aperture Radar (ASAR) SAR images was acquired from the Landmap Service. They were originally sourced from the European Space Agency (ESA) as level 1b Single Look Complex (SLC) products in slant range (table 1). Images were selected which had a small incidence angle, ranging from $22.76^{\circ}-23.23^{\circ}$ because Huang and Siegert (2006) found that the SAR intensity signal of fire scars decreased by $0.1 \mathrm{~dB}$ for each degree increase in the incidence angle. InSAR pairs were acquired for coherence analysis for dates before and after the fire (table 2). ERS-2 pairs with baselines less than the Sarmap (2007) recommended 500m threshold were selected for three of the four pairs, with $654 \mathrm{~m}$ for the fourth pair. 


\subsection{SAR pre-processing of intensity data}

SARScape 4.2 was used to pre-process the data listed in table 1 and table 2. Intensity images were produced by focusing and multilooking the data using five looks in azimuth and one look in range. Different speckle filtering algorithms were assessed for ERS-2 08/02/03 and ERS-2 28/06/03 (figure 2).

The multitemporal Degrandi filter applied to amplitude coregistered images smoothed speckle most effectively (figure $2 \mathrm{c}$ and $\mathrm{f}$ ). The filtered images were radiometrically calibrated and geocoded to British National Grid with a pixel size of $25 \mathrm{~m}$. The sigma nought $(\sigma 0)$ radar backscatter coefficient values were obtained in $\mathrm{dB}$ in ENVI $\odot$ band math using equation (1).

$$
10 * \operatorname{alog}_{10}(\mathrm{~b} 1)
$$

The $\mathrm{dB}$ filtered images were degraded in ENVI to a pixel size of $100 \mathrm{~m}$ using a nearest neighbour resampling method to match the spatial resolution of the CORINE land cover data and to preserve the original pixel values. A standard linear $2 \%$ contrast stretch was used to display all images.

\subsection{SAR pre-processing of coherence data}

Interferograms were generated for the ERS-2 pairs in table 2, followed by interferogram flattening to split the low frequency phase from the high frequency (differential) phase. The flattened interferogram was filtered to reduce phase noise and interferometric coherence, which was also produced during this pre-processing step. Phase unwrapping was then applied to the flattened interferogram using a region growing algorithm with a coherence threshold set at the typical value of 0.20 to avoid unwrapping islands. A phase-to-displacement conversion was applied to the unwrapped phase and was geocoded into British National Grid along with the coherence image. Coherence ranges between $0-1$ and is: 'The function of systemic spatial de-correlation, the additive noise, and the scene decorrelation that takes place between the two acquisitions' (Sarmap 2007, p.144).

$1=$ High coherence (temporal correlation, no change on the ground)

$0=$ No coherence (no correlation, temporal decorrelation, significant change on the ground over time) 
1 Table 1. SAR images used for the intensity analysis. The fire occurred on 18 April 2003 (108 JD). A.

2 Ascending Pass D. Descending Pass

\begin{tabular}{|c|c|c|c|c|c|c|c|}
\hline $\begin{array}{l}\text { SAR Data/ } \\
\text { Mode/ } \\
\text { Swath }\end{array}$ & $\begin{array}{c}\text { Acquisition } \\
\text { Date/Time } \\
\text { (ddmmyyyy } \\
\text { hr:mm) }\end{array}$ & $\begin{array}{c}\text { Time } \\
\text { relative to } \\
\text { fire } \\
\text { (JD Julian } \\
\text { day) }\end{array}$ & $\begin{array}{c}\text { Incidence } \\
\text { Angle } \\
\text { (IA) }\end{array}$ & $\begin{array}{l}\text { Az pixel } \\
\text { spacing } \\
\text { (m) }\end{array}$ & $\begin{array}{l}\text { Rg pixel } \\
\text { spacing } \\
\text { (m) }\end{array}$ & $\begin{array}{c}\text { Ground } \\
\text { Range } \\
\text { (GR) } \\
(\mathbf{m})\end{array}$ & $\begin{array}{l}\text { Pass } \\
\text { Type }\end{array}$ \\
\hline ERS-2 & $\begin{array}{c}08 / 02 / 2003 \\
11: 01\end{array}$ & $\begin{array}{c}-69 \text { days } \\
(39 \mathrm{JD})\end{array}$ & $23.23^{\circ}$ & 3.97 & 7.90 & 20.26 & $\mathrm{D}$ \\
\hline ERS-2 & $\begin{array}{c}15 / 03 / 2003 \\
11: 01\end{array}$ & $\begin{array}{l}-34 \text { days } \\
\text { (74 JD) }\end{array}$ & $23.23^{\circ}$ & 3.97 & 7.90 & 20.26 & $\mathrm{D}$ \\
\hline $\begin{array}{l}\text { ASAR IM } \\
\text { I2 }\end{array}$ & $\begin{array}{c}22 / 03 / 2003 \\
21: 37\end{array}$ & $\begin{array}{l}-27 \text { days } \\
(81 \mathrm{JD})\end{array}$ & $22.82^{\circ}$ & 4.04 & 7.80 & 20.00 & A \\
\hline $\begin{array}{l}\text { ASAR AP } \\
\text { I2 HH }\end{array}$ & $\begin{array}{c}03 / 04 / 2003 \\
10: 36\end{array}$ & $\begin{array}{l}\text {-15 days } \\
\text { (93 JD) }\end{array}$ & $22.76^{\circ}$ & 4.04 & 7.80 & 20.00 & $\mathrm{D}$ \\
\hline $\begin{array}{l}\text { ASAR AP } \\
\text { I } 2 \text { VV }\end{array}$ & $\begin{array}{c}03 / 04 / 2003 \\
10: 36\end{array}$ & $\begin{array}{l}-15 \text { days } \\
\text { (93 JD) }\end{array}$ & $22.76^{\circ}$ & 4.04 & 7.80 & 20.00 & $\mathrm{D}$ \\
\hline ERS-2 & $19 / 04 / 2003$ & $\begin{array}{l}+1 \text { day } \\
\text { (109 JD) }\end{array}$ & $23.05^{\circ}$ & 3.97 & 7.90 & 20.26 & D \\
\hline ERS-2 & $\begin{array}{c}24 / 05 / 2003 \\
11: 01\end{array}$ & $\begin{array}{l}\text { +36 days } \\
\text { (144 JD) }\end{array}$ & $23.21^{\circ}$ & 3.97 & 7.90 & 20.26 & $\mathrm{D}$ \\
\hline ERS-2 & $\begin{array}{c}28 / 06 / 2003 \\
11: 01 \\
\end{array}$ & $\begin{array}{l}\text { +71 days } \\
\text { (179 JD) }\end{array}$ & $23.28^{\circ}$ & 3.97 & 7.90 & 19.75 & $\mathrm{D}$ \\
\hline
\end{tabular}

\begin{tabular}{|c|c|c|c|c|c|}
\hline ERS-2 & Acquisition Date & Orbit & Track & Baseline (m) & Description \\
\hline Pair 1 & $08 / 02 / 2003$ 15/03/2003 & $40801 / 41302$ & 366 & 134 & Pre-fire \\
\hline Pair 2 & $15 / 03 / 200319 / 04 / 2003$ & $41302 / 41803$ & 349 & 349 & Pre/post-fire \\
\hline Pair 3 & $19 / 04 / 200324 / 05 / 2003$ & $41803 / 42304$ & 366 & 147 & Post-fire \\
\hline Pair 4 & $24 / 05 / 2003 \quad 28 / 06 / 2003$ & $42304 / 42805$ & 366 & 654 & Post-fire \\
\hline
\end{tabular}

7

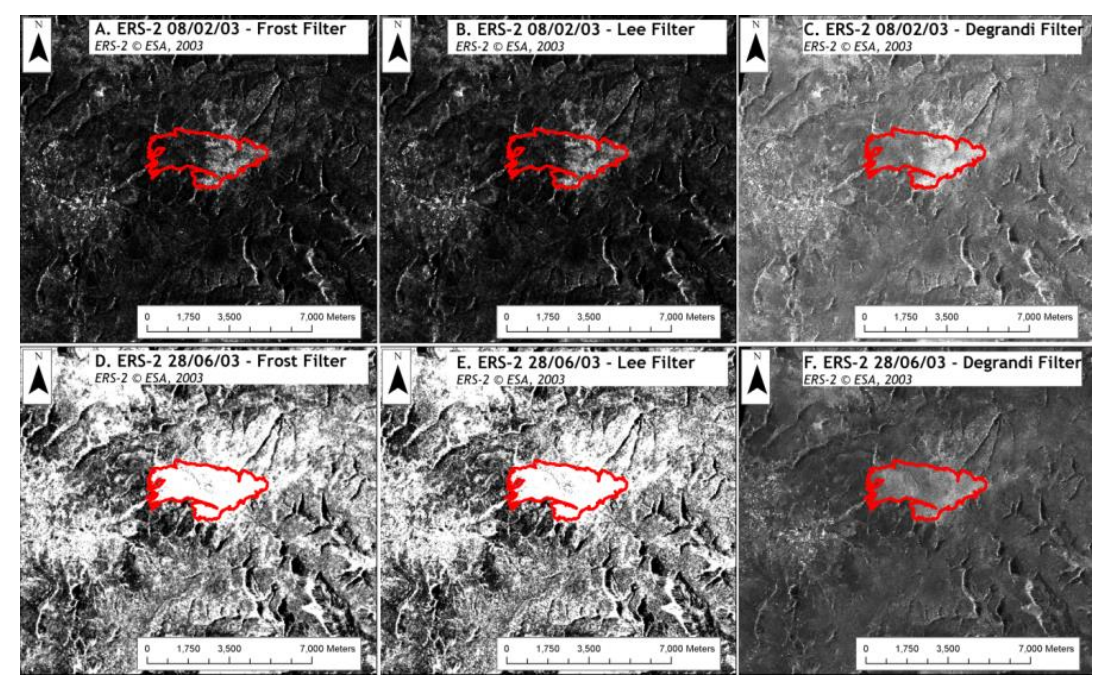

Figure 2. (a-f) Comparison of filtering methods for ERS-2 of the Bleaklow fire scar for 08/02/03 (pre-fire, top row) and ERS-2 28/06/03 (post-fire, bottom row): Frost (a,d), Lee (b,e), multitemporal Degrandi (c,f). 


\subsection{Land Cover and Wetness Factors}

ArcGIS 10 was used to extract SAR intensity and InSAR coherence values using a stratified random sampling technique. The sample consisted of 15 sample points in total inside the fire scar and 15 sample points in total outside the fire scar for each of the three CORINE land cover classes: peat bog, moors and heathland, and natural grassland (figure 1). The average of 5 sample points at a spatial resolution of $100 \mathrm{~m}$ per pixel for each land cover type was adequate for capturing the spatial accuracy without losing the spatial precision of the data for land cover classes both inside and outside the fire scar.

To provide an indirect indicator of surface wetness, total daily precipitation was collected from the Upper North Grain (UNG) weather station, located $4 \mathrm{~km}$ southeast of the fire scar (figure 3). The UNG precipitation data starts on JD 66. However, the SAR time-series begins at JD 39, so precipitation data from the Met Office Integrated Data Archive System (MIDAS) for Woodhead Reservoir (WR) weather station is provided for the first SAR image of the time-series (figure 3). UNG was used as the primary precipitation dataset for the remaining SAR images. There is high spatial and temporal variability of precipitation events, as shown in figure 3; magnitude and duration varies between the two sites but the temporal pattern is consistent.

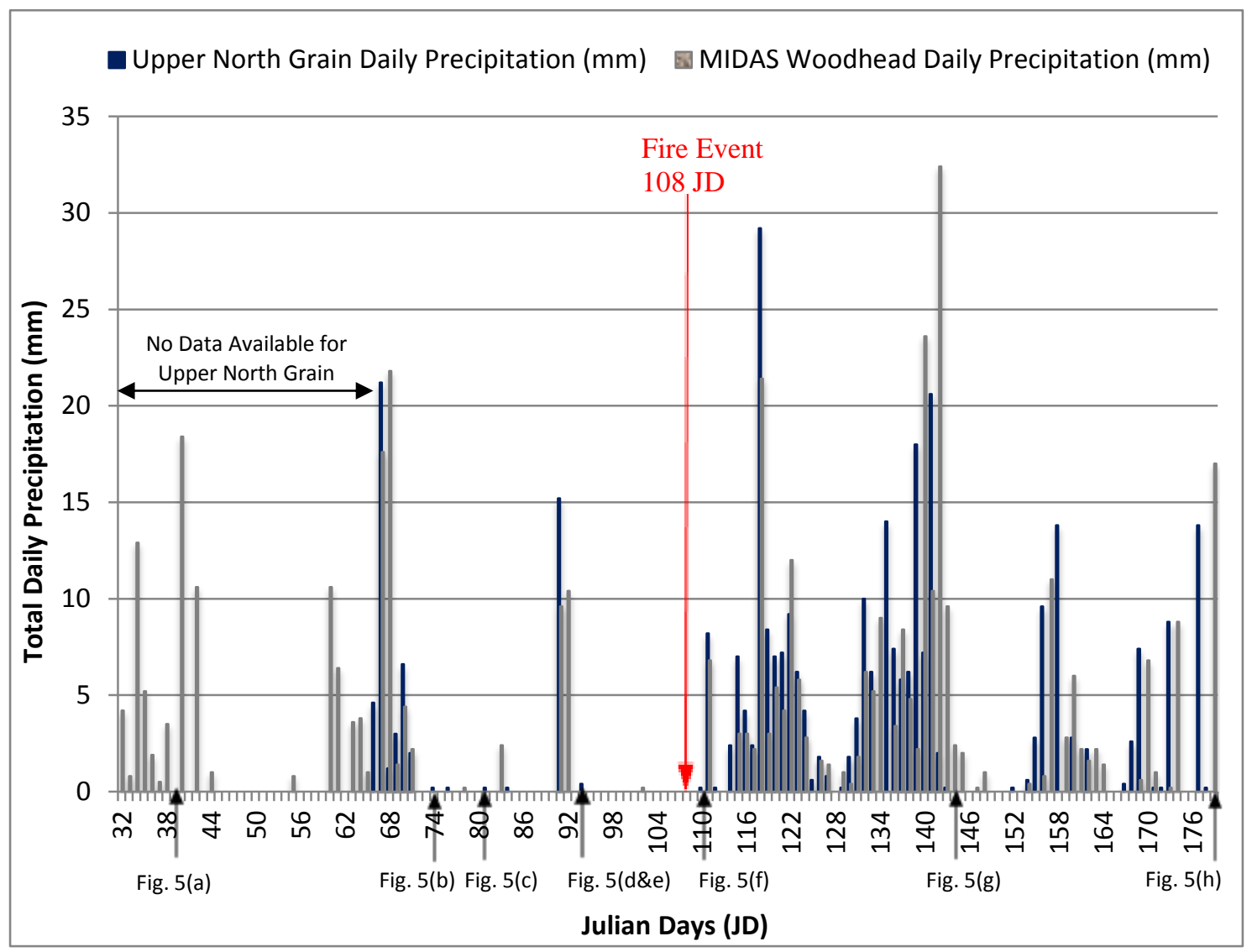

Figure 3. Total daily precipitation ( $\mathrm{mm}$ ) from 01/02/03 - 28/06/03 at Woodhead, 4km north of the fire scar data provided by MIDAS hosted by The British Atmospheric Data Centre (BADC) and total daily precipitation (mm) from 07/03/03 - 28/06/03 at Upper North Grain, 4km southwest of the fire scar. 


\section{Results and discussion}

\subsection{SAR Intensity}

Figure 4 shows how average SAR intensity values for CORINE land cover classes inside and outside the Bleaklow fire scar change over time. Sites outside the fire scar were included to establish the baseline variability due to other factors such as vegetation seasonality and heterogeneity. Sites of the same land cover classes inside and outside the fire scar were compared to assess the background effect of land cover on the fire signal.

\subsubsection{Pre-fire intensity analysis}

Figure 5 shows a time series of SAR intensity images before the fire (figures 5a-e) and after it (figures 5f-h). The CORINE class 'peat bog' represents exposed, badly eroded peat created by earlier fire events. Inside the fire scar, peat bog is located at the eastern end. Peat bog inside the fire scar had the overall highest pre-fire intensity (figure 4); with an average intensity value of $0.49 \mathrm{~dB}$ for the ASAR Alternating Polarisation (AP) VV and $\mathrm{HH}$ images (figures $5 \mathrm{~d}-\mathrm{e}$ ). The peat bog is spatially detected in the pre-fire images as greater backscatter of the radar signal, visualised by bright pixels (figure 5ae). This spatial pattern is less distinct in the ASAR IM image (figure 5c). The peat bog class is spatially heterogeneous across the study site; inside the fire scar, its pre-fire SAR intensity signal in figure $5 \mathrm{a}-\mathrm{b}$ is $6-7 \mathrm{~dB}$ higher than outside. The reason for this could be increases in soil moisture as a result of precipitation, which is detected inside the fire scar due to the eroded nature of the peat bog class in this area, caused by previous fire events (figure 1, red dots). Similar results have been reported in boreal forested areas in Canada by Bourgeau-Chavez et al. (2002) During JD 72 - JD 90, little precipitation occurred, followed by one notable precipitation event on JD 91 with $15.2 \mathrm{~mm}$ of precipitation (figure 3). SAR intensity increased in response to this event for all land cover types, irrespective of whether the land cover class was inside or outside the future fire scar (JD 108); differences between classes of the same type were reduced to $1-2 \mathrm{~dB}$ (figure 4 ).

After the precipitation event on JD 91 and before the fire event, there was a two week dry period which is expressed as an overall downward trend in SAR intensity signal for all land cover classes. This agrees with Gimeno et al. (2004), who found that scenes taken during the dry season exhibit lower intensity values (figure 4). 
Figure 4. Average intensity values (dB) inside and outside the Bleaklow fire scar for CORINE land cover classes. NB. 93 JD provides the average intensity for AP HH/VV shown in fig. $5 \mathrm{~d}$ and fig. $5 \mathrm{e}$.

\subsubsection{Post-fire intensity analysis}

The Bleaklow fire occurred on JD 108, with the first post-fire image acquired on JD 109 , two days before the end of the dry period (figure 3 ). The intensity values for all CORINE land cover classes decreased by at least $3 \mathrm{~dB}$ during the dry period (JD $93-$ JD 110). The SAR response to the fire, however, was not significantly different from the previous dry period (JD 72 - JD 90), so it is difficult to establish whether SAR is responding primarily to dry conditions, the fire event itself, or to a combination of both (figure 4). However, one day post-fire, figure $5 \mathrm{f}$ (iii) shows a new spatial pattern within the fire scar; for the first time, a general brightening is seen in the western part of the fire scar within the former moors and heathland class, in response to the combustion of the above ground biomass. 

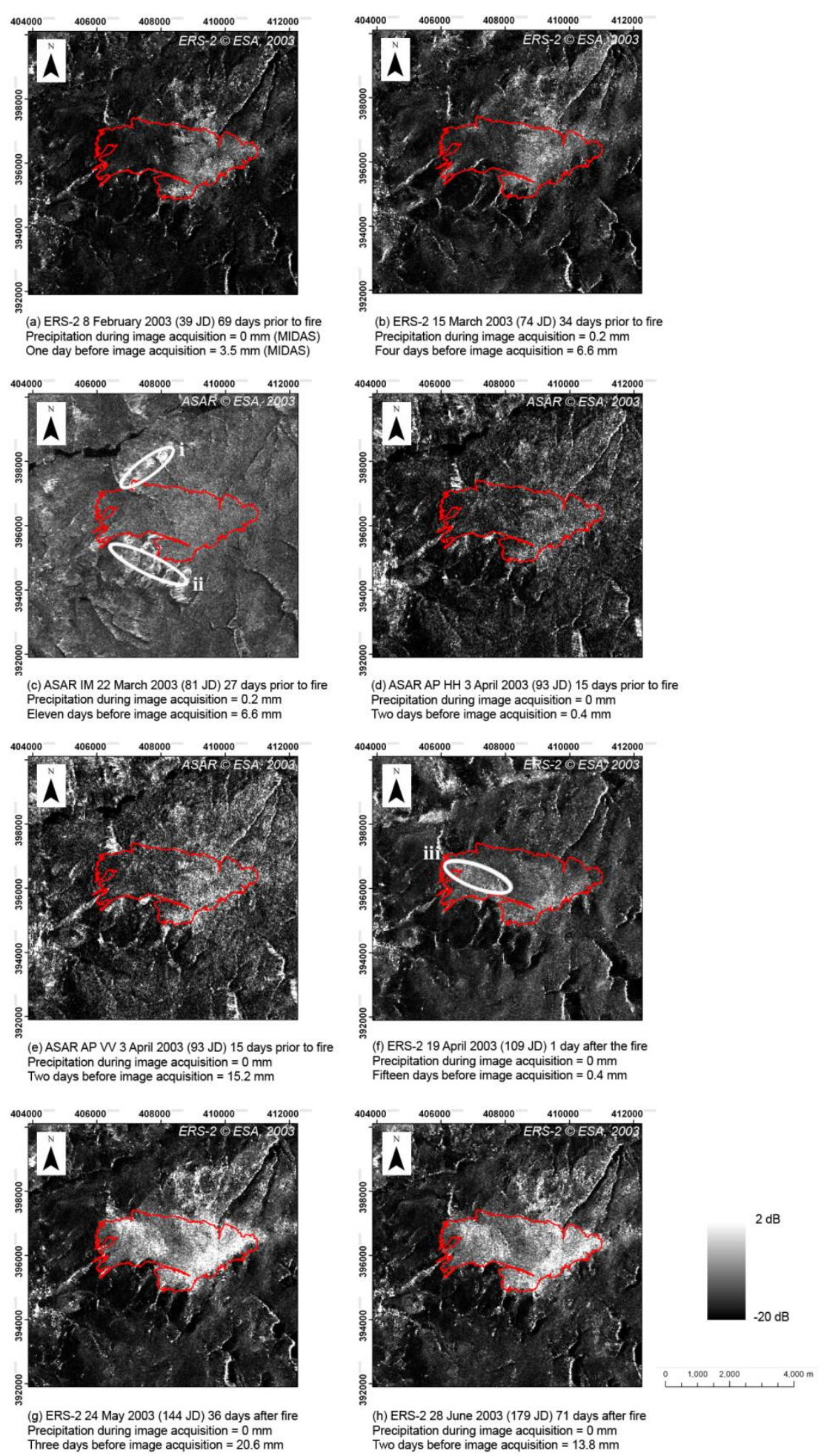

Figure 5. Time series of SAR intensity images for the Bleaklow 18 April 2003 wildfire. Key spatial patterns are annotated (i / ii) ascending pass topographic features and (iii) removal of moors and heathland vegetation after the fire. N.B. Precipitation values for (a) MIDAS (b-h) Upper North Grain. 
Table 3. Spatial differences in intensity response for land cover classes during the post-fire wet period

\begin{tabular}{lccc}
\hline Wet Period: Land Cover Class & Inside Fire Scar & Outside Fire Scar & Intensity Difference dB \\
\hline 144 JD: Peat bog & 0.84 & -8.00 & 7.16 \\
144 JD: Moors and Heathland & -1.79 & -4.06 & 2.27 \\
144 JD: Natural Grassland & -3.59 & -10.04 & 6.45 \\
\hline 179 JD: Peat bog & -0.86 & -6.96 & 6.10 \\
179 JD: Moors and Heathland & -2.68 & -4.21 & 1.53 \\
179 JD: Natural Grassland & -3.78 & -9.43 & 5.65 \\
\hline
\end{tabular}

The intense Bleaklow fire was followed by a very wet post-fire period from JD 111 onwards (figure 3). Differences in post-fire response of the intensity signal for land cover classes inside the fire scar were compared to the same land cover classes outside the fire scar to assess sensitivity of fire scar persistence to land cover type. Differences were most evident on JD 144 and JD 179 when precipitation had occurred (table 3). Significant precipitation events were recorded at the adjacent weather stations e.g. UNG $20.6 \mathrm{~mm}$ on JD 141 and at Woodhead - 23.6mm on JD 140 and $32.4 \mathrm{~mm}$ on JD 142 (figure 3). All three land cover classes increased in intensity inside the fire scar. This is most pronounced for the peat bog class, with intensity values $7.16 \mathrm{~dB}$ higher inside the fire scar compared to those outside on JD 144, and 6.10 dB higher inside the fire scar compared to outside on JD 179. During this wet period, the pre-existing exposed peat bog exhibited the highest intensity values at $0.84 \mathrm{~dB}$ (JD 144) and $-0.86 \mathrm{~dB}$ (JD 179). We believe the most likely explanation is that the intense heat from the fire event caused the underlying and previously exposed peat to char and become hydrophobic (Atanassova and Doerr 2011). The hydrophobic nature of the peat provides ground conditions for shallow depression pools of water to form (around $10 \mathrm{~cm}-30 \mathrm{~cm}$ in size) after several significant precipitation events, which then causes radar backscatter to increase due to the dielectric properties of water (figure 4 and figure $5 \mathrm{~g}-\mathrm{h}$ ).

Natural grassland shows a similar pattern to peat bog, with SAR intensity inside the fire scar $6.45 \mathrm{~dB}$ higher on JD 144 and $5.65 \mathrm{~dB}$ higher on JD 179. We suggest that the increased intensity for natural grassland is explained by combustion of the grassland biomass, which then made the underlying newly exposed peat more prone to surface wetness. Outside the fire scar, natural grassland is the class with the lowest SAR intensity on both post-fire dates; $-10.04 \mathrm{~dB}$ on JD 144 and $-9.43 \mathrm{~dB}$ on JD 179. This low backscatter return could be due to fine grassland vegetation creating a specular scattering effect on the short wavelength of the C-band data, as the grassland would appear smooth and uniform so reducing the return of the SAR signal producing a similar dark response to the reservoirs (figure $5 \mathrm{~g}-\mathrm{h}$ ). The intensity difference due to fire is not as pronounced for moors and heathland, as can be seen in figure 4 .

\subsubsection{Discussion of intensity results}

The time-series of ERS-2 and ASAR data illustrates that SAR images spatially detect the Bleaklow fire scar in a moorland habitat. This result also suggests that SAR should also be investigated as a surrogate for spatially-distributed information on surface wetness in moorland habitats; it could be a helpful tool (in the long-term) for understanding soil moisture for such a spatially heterogeneous environment.

The combined effect of a fire followed by precipitation events resulted in the area of the fire scar being clearly detected. Figure $5 \mathrm{~g}$-h shows a strong intensity signal (bright pixels) within the perimeters of the fire scar following the precipitation events. Bourgeau-Chavez et al. $(1997,2002,2007)$ reported similar results for boreal burned forests such as in Alaska where fire scars post-burn were easily detected due to 
increases in soil moisture caused by snowmelt and rainfall months after the fire event. Their linear regression results show ERS-2 backscatter positively correlated to soil moisture for light, moderate and severe burns (Bourgeau-Chavez et al. 2007). This positive correlation between SAR intensity and soil moisture has also been used for applications such as monitoring ground conditions of wetlands in southern Florida (Kasischke et al. 2003) and can be assumed to apply to moorland environments in the UK based on the temporal results of this Bleaklow case study. For the current study, it is not known whether snow melt as well as precipitation would have contributed to any variation in soil moisture, as is identified in Kasichke et al. (2007). It is unlikely during the fire event period in April, but could be a contributing factor for peaks in SAR intensity for the badly eroded peat bog class inside the fire scar (bare peat) during the winter and early spring period (figure $5 \mathrm{a}-\mathrm{b}$ ). A wet post-fire period is typical in UK moorlands, indeed Fire and Rescue Services find it difficult to extinguish deep-seated smouldering peat fires such as this, and it is normal for them to be extinguished in due course by precipitation.

To summarise, it is evident from figure 5 that a large wildfire event which is followed (as is typical) by heavy precipitation in UK moorlands, can produce a fire scar which is detectable spatially on the SAR scenes. Furthermore, it could be detected with regular SAR images as much as 71 days after the fire event, which is a benefit of using radar data as compared to optical or thermal data. Table 3 shows that the persistence of the wildfire scar in the landscape is strongest for the peat bog and grassland classes. Potentially this technique could save time and money in monitoring the impact of wildfire events and is capable of providing results several months after the event.

\subsection{SAR Coherence}

SAR coherence was used as another parameter to detect the Bleaklow fire scar. Four pairs of ERS-2 InSAR coherence was generated (table 2 and figure 6). SAR coherence was low for the first InSAR pair, which means that there was significant change on the ground pre-fire for all three land cover classes and could be due to phenological change during this 35 day period. It ranged from $0.14-0.24$, depending on the CORINE land cover class (figure 7). There was an unexpected slight increase in coherence for the second InSAR pair, shortly before and immediately after the fire. The exception was, the burnt natural grassland inside the fire scar, which remained constant at 0.19 (figure 7). It had been expected that combustion of biomass would have decreased coherence inside the fire scar for moors and heathland and natural grassland classes.

The first of the post-fire InSAR pairs (pair 3 JD 109 - JD 144) (figure 6c) showed a noticeable increase in coherence for all three CORINE land cover classes inside the fire scar. This was especially true for the burnt moors and heathland class where the coherence value increased by 0.18 , from $0.29-0.47$ between the second and third pairs. A similar 0.17 increase was found for burnt natural grassland, from $0.19-0.36$. In comparison, the coherence of burnt peat bog did also increase between the second and third coherence pair, but only by 0.07 , which is less than half the coherence response of burnt moors and heathland and natural grassland. Visually, the post-fire increase in coherence can be seen by the marked relative brightness of the moors and heathland and natural grassland pixels on the west side of the fire scar compared to equivalent areas of moors and heathland and natural grassland outside the fire scar (figure 6c). This suggests that it was the biomass combustion within the fire scar keeping land cover constant whereas unburned areas changed most likely due to phenology. 

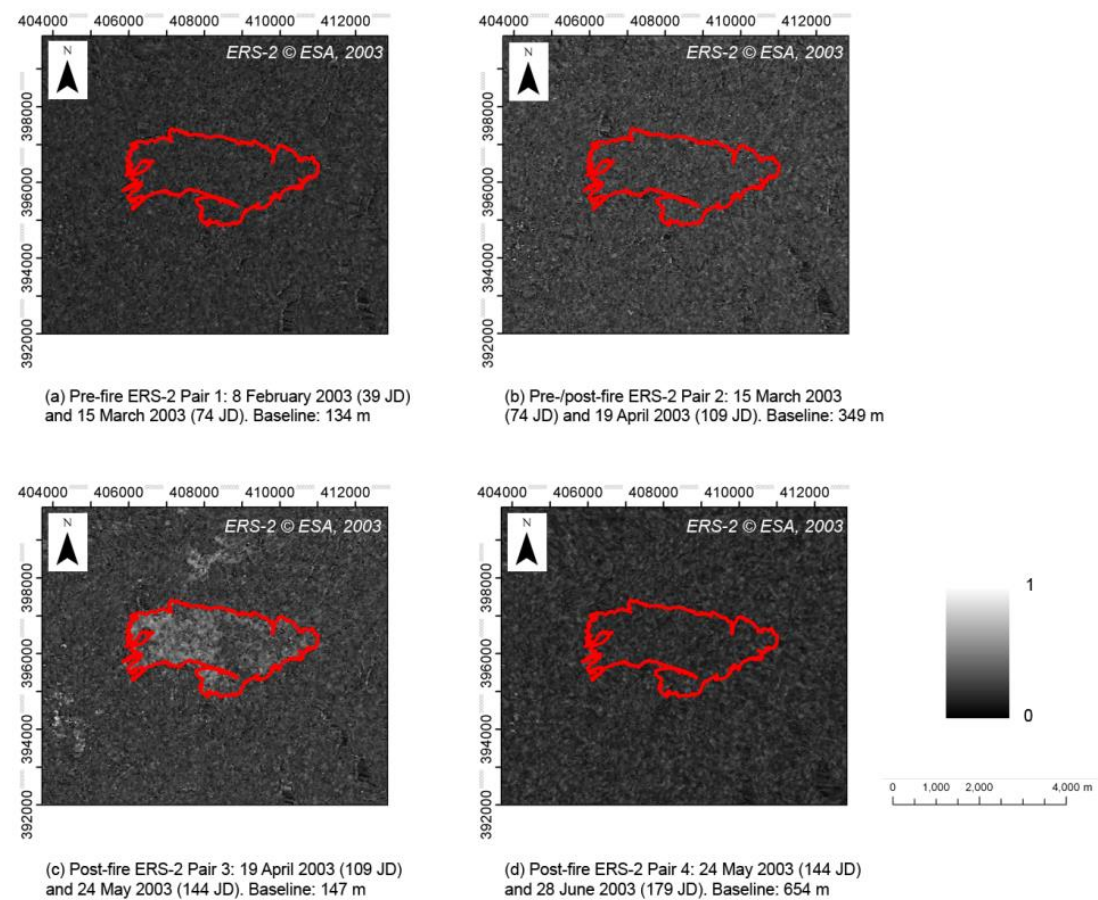

Figure 6. InSAR coherence images for Bleaklow. Each produced from a pair of SAR images (Table 2)

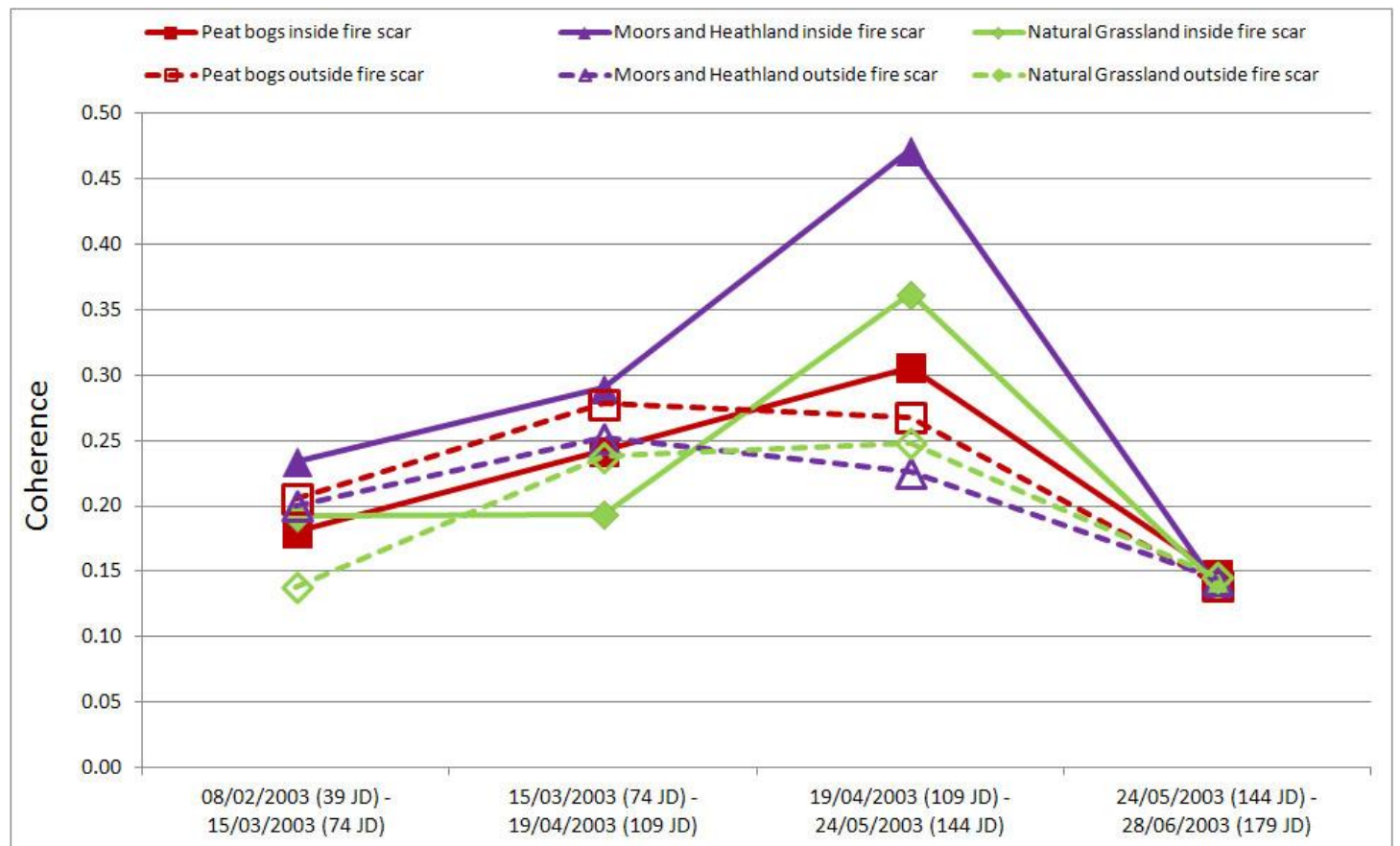

Figure 7. Trend in average coherence of three CORINE land cover classes, inside and outside the Bleaklow fire scar. Fire date 18 April 2003 (JD 108).

For each land cover in turn, the aim was to test whether temporal variability in coherence (between the four coherence pair dates) was greater than their spatial variability (within the coherence sample points). A series of null hypotheses $\left(\mathrm{H}_{0}\right)$ were set-up that there was no significant difference in the variance between the four InSAR coherence pairs compared to the variance within the pairs. The Analysis of Variance 15 (ANOVA) test was run separately for the three land cover types, both inside the fire scar 
and outside the fire scar (6 ANOVA runs in total, table 4). The F statistic compares the between group variance (between ERS-2 InSAR pairs over time for a given land cover class) and the within group variance (spatially within the five coherence sample points for a given land cover class) (table 4). The variation within the five coherence sample points for each land cover class is not significant. However the variation between ERS2 InSAR pairs for a given land cover class was significant. The land cover classes exhibiting the greatest between group variance were the moors and heathland class inside the fire scar, with an F statistic of 48.30; natural grassland inside the fire scar with an F statistic of 23.88 and peat bog outside of the fire scar with an F statistic of 7.75. The F statistic for all classes exceeded the F critical value of 3.24 , confirming that there is a significant difference between the ERS-2 InSAR coherence pairs at the 5\% significance level, so the null hypothesis can be rejected. The P-value indicates that there would be a very low probability $(<0.05)$ that the calculated $F$ value had been obtained by chance (random error) alone. The ANOVA test provides evidence that there is a significant difference temporally between InSAR coherence pairs for all land cover classes, but especially for natural grassland and moors and heathland inside the fire scar.

Figure 7 shows that for all land cover classes outside the fire scar the InSAR coherence remained low. The ANOVA test also shows much lower F statistics for land cover classes located outside the fire scar from $3.52-7.75$. This result suggests that there was change occurring on the ground within these unburned land cover classes, which could be related to phenological changes of vegetation especially for the natural grassland and moors and heathland classes. The removal of vegetation by the fire reduced this background phenological signal within the fire scar. Pre-fire land cover is therefore a key factor affecting the coherence response; pre-existing exposed peat from earlier fires, which burnt again in the April 2003 fire, showed a smaller increase in coherence; that is, it exhibited more change post-fire compared to newly burnt vegetation.

Table 4. Analysis of Variance Test (ANOVA) to compare the four ERS-2 coherence pairs

\begin{tabular}{|c|c|c|c|c|c|}
\hline $\begin{array}{l}\text { ANOVA Test } \\
\text { Source of variation for coherence pairs: } \\
\text { BG = Between Groups of four ERS-2 pairs } \\
\text { for a given land cover type (temporal); } \\
\text { WG = Within Groups coherence sample } \\
\text { points for a given land cover type (spatial) }\end{array}$ & $\begin{array}{l}\text { Sum } \\
\text { of Sq }\end{array}$ & df & F stat & P-value & F critical \\
\hline BG: Peat bog inside fire scar & 0.07 & 3 & 4.74 & 0.015 & 3.24 \\
\hline WG: Peat bog inside fire scar & 0.08 & 16 & & & \\
\hline BG: Moors \& heathland inside fire scar & 0.30 & 3 & 48.30 & $3.046 \times 10^{-8}$ & 3.24 \\
\hline WG: Moors \& heathland inside fire scar & 0.03 & 16 & & & \\
\hline BG: Natural grassland inside fire scar & 0.14 & 3 & 23.88 & $3.773 \times 10^{-6}$ & 3.24 \\
\hline WG: Natural grassland inside fire scar & 0.03 & 16 & & & \\
\hline BG: Peat bog outside fire scar & 0.06 & 3 & 7.75 & 0.002 & 3.24 \\
\hline WG: Peat bog outside fire scar & 0.04 & 16 & & & \\
\hline BG: Moors \& heathland outside fire scar & 0.03 & 3 & 4.09 & 0.025 & 3.24 \\
\hline WG: Moors \& heathland outside fire scar & 0.04 & 16 & & & \\
\hline BG: Natural grassland outside fire scar & 0.05 & 3 & 3.52 & 0.039 & 3.24 \\
\hline WG: Natural grassland outside fire scar & 0.08 & 16 & & & \\
\hline
\end{tabular}


Exceeding the critical baseline for InSAR pre-processing is the most likely cause of the overall downward trend in coherence for all CORINE land cover classes for the fourth InSAR pair, as the initial baseline is $654 \mathrm{~m}$, which is higher than the maximum recommended baseline of $500 \mathrm{~m}$ (figure $6 \mathrm{~d}$ ). In addition, there is likely to have been much change on the ground, such as phenological change of vegetation outside the fire scar and also the continuation of a reseeding programme on the east side of the fire scar which could contribute to the decrease in coherence. If the fourth InSAR pair had not been affected by exceeding the critical baseline, the expected result would be for coherence to remain high within the fire scar, as was the case for the third InSAR pair.

\section{Conclusion}

This paper has shown that in a degraded moorland environment, SAR intensity can be used as a tool to spatially detect a large wildfire scar, especially where peat is left eroded by previous fire events and remains unvegetated. The ERS- 2 and ASAR images detected bare peat from previous fire occurrence in the pre-18 April 2003 images where it dominates the CORINE peat bog class inside the future fire scar area. Pre-fire precipitation events further enhanced this pre-existing bare peat as a bright area on the SAR intensity images by increasing soil moisture.

Post-fire, from JD 108, soil moisture repellency is likely to increase due to the exposure of peat to intense heat (Atanassova and Doerr 2011). Depression pools of water on the burnt peat surface form as a result of intense precipitation events and enhance the SAR backscattering effect. Such precipitation events are common after a fire event in a moorland environment.

Detectability of the fire scar using SAR intensity varied with the pre-fire land cover. The CORINE peat bog class was the most responsive, with SAR intensity values being $6-7 \mathrm{~dB}$ higher on newly re-burnt peat bog relative to peat bog outside the fire scar. Pre-existing land cover (explained here partly by fire history) combined with precipitation are therefore key factors jointly enhancing fire scar detectability on SAR intensity images. InSAR coherence provides another SAR parameter for aiding the detection of moorland fire scars. The most marked change was an increase in coherence across all three classes inside the newly-created fire scar between JD 109 and 144. Coherence increased in this post-fire period most markedly for burnt moors and heathland and natural grassland classes, responding to the loss of biomass which occurred on JD 108. A complementary decrease in coherence for the same classes in unburned areas is likely due to phenological change.

The importance of SAR parameters and pre-processing method should be acknowledged. For example, the recommendations are: to use images with a small incidence angle, apply a multi-temporal filtering algorithm such as Degrandi; and choose an InSAR pair for coherence analysis which has a low baseline (less than 500m) (Sarmap, 2007). Equally, understanding environmental variables such as precipitation, fire history and land cover is critical in interpreting the SAR signal both for SAR intensity and InSAR coherence.

This study has also shown how a wildfire in a degraded peat moorland environment can detect a fire scar that persists in the landscape for months after the fire event, or even years when fire history of the area is considered. In this analysis, SAR intensity data still detected the Bleaklow 18 April 2003 wildfire scar 71 days after the fire event. This result is encouraging and a unique finding for moorland environments. It suggests that SAR is a potential tool for assessing the extent and location of moorland wildfire scars and their long-term recovery at the landscape scale, where cloud can be an issue for optical data and thermal data only provides a short-term signal. 
Future studies are likely to investigate the use of SAR intensity and coherence for detecting fire scars of different sizes, precipitation history, topography and less generalised land cover classes in the PDNP in order to disentangle controls on the SAR signal. A spatial analysis approach involving SAR image classification of both SAR Cband and L-band data may be explored for automating the detection of wildfire scars for degraded peat moorland environments such as this.

\section{Acknowledgements}

This research was funded and supported by Mimas and the School of Environment and were kindly provided by the Landmap Service, Mimas under the European Space Agency (ESA) Category 1 Project 2999. Many thanks to the European Environment Agency (EEA) for access to CORINE Land Cover data; Fire logs and fire scar data from Moors for the Future; PDNP Fire Operations Group for information about the fire; Martin Evans and Juan Yang at SED for access to Upper North Grain weather station data and the British Atmospheric Data Centre (BADC) for access to the Woodhead weather station data.

\section{References}

Anderson, P., Buckler, M. \& Walker, J. (2009) Moorland restoration: potential and progress. IN Bonn, A., Allott, T., Hubacek, K. \& Stewart, J. (Eds.) Drivers of Environmental Change in Uplands. Oxon, Routledge.

Armitage, R. P., Ramirez, F. A., Ogunbadewa, E. Y. \& Danson, F. M. (2007) Comparison of AVHRR and MODIS Cloud Products for Estimating Cloud Cover Probabilities for the United Kingdom. 2007 Annual Conference of the Remote Sensing \& Photogrammetry Society; Challenges for Earth Observation: Scientific, Technical and Commercial. Newcastle University.

Atanassova, I. \& Doerr, S. H. (2011) Changes in soil organic compound composition associated with heat-induced increases in soil water repellency. European Journal of Soil Science, 62, 516-532.

Bourgeau-Chavez, L. L., Harrell, P. A., Kasischke, E. S. \& French, N. H. F. (1997) The detection and mapping of Alaskan wildfires using a spaceborne imaging radar system. International Journal of Remote Sensing, 18, 355-373.

Bourgeau-Chavez, L. L., Kasischke, E. S., Brunzell, S., Mudd, J. P. \& Tukman, M. (2002) Mapping fire scars in global boreal forests using imaging radar data. International Journal of Remote Sensing, 23, 4211-4234.

Bourgeau-Chavez, L. L., Kasischke, E. S., Riordan, K., Brunzell, S., Nolan, M., Hyer, E., Slawski, J., Medvecz, M., Walters, T. \& Ames, S. (2007) Remote monitoring of spatial and temporal surface soil moisture in fire disturbed boreal forest ecosystems with ERS SAR imagery. International Journal of Remote Sensing, 28, 2133-2162.

CCVE (2005) Risk Workshop: Moorland Wildfires in the Peak District. Technical Report, Climate Change and the Visitor Economy. Sustainability Northwest, Manchester, and Centre for Urban and Regional Ecology (CURE), University of Manchester.

EFFIS (2011) European Forest Fire Information System. Available from http://effis.jrc.ec.europa.eu/current-situation [accessed 28 May 2011].

Evans, M. \& Lindsay, J. (2010) High resolution quantification of gully erosion in upland peatlands at the landscape scale. Earth Surface Processes and Landforms, 35, 876 - 886. 
Gimeno, M., San-Miguel-Ayanz, J. \& Schmuck, G. (2004) Identification of burnt areas in Mediterranean forest environments from ERS-2 SAR time series. International Journal of Remote Sensing, 25, 4873-4888.

Huang, S. \& Siegert, F. (2004) ENVISAT multisensor data for fire monitoring and impact assessment. International Journal of Remote Sensing, 25, 4411-4416.

Huang, S. L. \& Siegert, F. (2006) Backscatter change on fire scars in Siberian boreal forests in ENVISAT ASAR wide-swath images. IEEE Geoscience and Remote Sensing Letters, 3, 154-158.

Kasischke, E. S., Bourgeau-Chavez, L. L. \& Johnstone, J. F. (2007) Assessing spatial and temporal variations in surface soil moisture in fire-disturbed black spruce forests in Interior Alaska using spaceborne synthetic aperture radar imagery Implications for post-fire tree recruitment. Remote Sensing of Environment, 108, 42-58.

Kasischke, E. S., Smith, K. B., Bourgeau-Chavez, L. L., Romanowicz, E. A., Brunzell, S. \& Richardson, C. J. (2003) Effects of seasonal hydrologic patterns in south Florida wetlands on radar backscatter measured from ERS-2 SAR imagery. Remote Sensing of Environment, 88, 423-441.

Legg, C. A. (1991) A Review of Landsat MSS image acquisition over the United Kingdom, 1976-1988, and the implications for operational remote sensing. International Journal of Remote Sensing, 12, 93-106.

McEvoy, D. H., J.F., Cavan, G., Aylen, J., Lindley, S., McMorrow, J. \& Glynn, S. (2006) Climate Change and the Visitor Economy: the challenges and opportunities for England's Northwest. Sustainability Northwest (Manchester) and UKCIP (Oxford).

McMorrow, J., Lindley, S., Aylen, J., Cavan, G., Albertson, K. \& Boys, D. (2009) Moorland wildfire risk, visitors and climate change. IN Bonn, A., Allott, T., Hubacek, K. \& Stewart, J. (Eds.) Drivers of Environmental Change in Uplands. Oxon, Routledge.

Menges, C. H., Bartolo, R. E., Bell, D. \& Hill, G. J. E. (2004) The effect of savanna fires on SAR backscatter in northern Australia. International Journal of Remote Sensing, 25, 4857-4871.

Rykhus, R. \& Zhong, L. (2011) Monitoring a boreal wildfire using multi-temporal Radarsat-1 intensity and coherence images. Geomatics, Natural Hazards and Risk, 2, 15 - 32.

Sarmap (2007) The SAR Guidebook: Examples Based on SARscape. CREASO. Available from http://www.ittvis.com/portals/0/pdfs/envi/SAR_Guidebook.pdf [accessed 12 Oct 2012].

Worrall, F. \& Evans, M. G. (2009) The carbon budget of upland peat soils. IN Bonn, A., Allott, T., Hubacek, K. \& Stewart, J. (Eds.) Drivers of Environmental Change in Uplands. Oxon, Routledge. 